\title{
Prediction of Drought Risk Based on the WRF Model in Yunnan Province of China
}

\author{
Chunhong Zhao, ${ }^{1,2,3}$ Xiangzheng Deng, ${ }^{1,2}$ Yongwei Yuan, ${ }^{4}$ Haiming Yan, ${ }^{5}$ and Hong Liang ${ }^{6}$ \\ ${ }^{1}$ Institute of Geographic Sciences and Natural Resources Research, Chinese Academy of Sciences, Beijing 100101, China \\ ${ }^{2}$ Center for Chinese Agricultural Policy, Chinese Academy of Sciences, Beijing 100101, China \\ ${ }^{3}$ University of Chinese Academy of Sciences, Beijing 100049, China \\ ${ }^{4}$ Faculty of Resources and Environmental Science, Hubei University, Wuhan, Hubei 430062, China \\ ${ }^{5}$ State Key Laboratory of Water Environment Simulation, School of Environment, Beijing Normal University, Beijing 100875, China \\ ${ }^{6}$ Shenzhen Environmental Monitoring Center, Shenzhen, Guangdong 518049, China
}

Correspondence should be addressed to Xiangzheng Deng; dengxz.ccap@gmail.com

Received 15 June 2013; Accepted 27 August 2013

Academic Editor: Hongbo Su

Copyright (C) 2013 Chunhong Zhao et al. This is an open access article distributed under the Creative Commons Attribution License, which permits unrestricted use, distribution, and reproduction in any medium, provided the original work is properly cited.

\begin{abstract}
Yunnan province is the core region of the drought in the Southwest China, which makes the region become the hot spot in the meteorological research. However, among the various influencing factors of the drought in Yunnan province, the influence of the land use/cover change (LUCC) on the drought has not been quantitatively analyzed. The LUCC in recent decades was first quantitatively analyzed in this study. Given the fact that severe drought in Yunnan province is mainly due to much-less-than-normal precipitation and much-warmer-than-normal surface temperature, this study focused on the future spatiotemporal heterogeneity of the temperature and precipitation, which have great impacts on the drought. Finally, the influencing factors of drought in Yunnan province were simulated with the Weather Research and Forecasting (WRF) model, and the risk of drought was spatially analyzed with the meteorological drought composite index. The results indicate that the large-area forest plays a more important role in alleviating the risk of drought than other vegetation types do. Besides, the changes of the landscape structure resulting from the urban expansion play a significant role in intensifying the risk of drought.
\end{abstract}

\section{Introduction}

Drought is one of the world's most common and damaging disasters [1], causing the global damages of tens of billions of dollars and affecting more people than any other devastating climate-related hazards [2]. Being located in East Asia, China has suffered long-lasting and severe droughts during the latter half of twentieth century, which caused large economic and societal losses [3,4]. The once-in-a-century drought swept across Southwest China (including Yunnan, Guizhou, Guangxi, Sichuan, and Chongqing) from the summer of 2009 to the spring of 2010. It subjected over 16 million of people and 11 million of livestocks to water shortages, devastated crops across more than 4 million hectares of farmland and made $25 \%$ of them yield no harvest. Besides, most rivers shrank to
$30-80 \%$ of their normal volume, and some dried up completely.

Yunnan province is located to the southeast of QinghaiTibet Plateau $\left(100^{\circ} \mathrm{E}-110^{\circ} \mathrm{E}, 23^{\circ} \mathrm{N}-28^{\circ} \mathrm{N}\right)$ and is the core region of the drought in the Southwest China. There is frequent drought in the Yunnan province, which makes the region become the hot spot in the meteorological research papers [5]. The frequent drought is closely related with the special geographic position of the Yunnan province. Yunnan province is a typical plateau at lower latitudes, and the three cutting-edge issues in the meteorological fields, that is, the mega relief, lower latitudes, and tropical oceans, concentrate in this region and consequently lead to many distinctive climatic phenomena $[6,7]$. On the one hand, it is located in the fragile region of the monsoon climate zone and is in the junction of 
East Asian monsoon and South Asian monsoon, where there is great variability of the climate [8] and the influencing factors of the weather and climate are extremely complex $[9,10]$. On the other hand, the land use/cover change (LUCC) plays an important role in influencing the drought disaster and climatic anomaly. The LUCC can change the properties of the underlying surface and lead to the local and regional climate changes [11]. However, among the various influencing factors of drought, the influence of the LUCC on the drought has not been quantitatively analyzed.

There is a lack of the forecast of the scenario of drought in the future and identification of the effects of the LUCC in many of the research papers on the drought in the Yunnan province. Besides, the relevant research papers mainly depend on the diagnosis with the historical statistical data [12, 13], which is of limited guiding significance for taking reasonable disaster prevention measures. As for the research on the climate and risk of drought in Yunnan Province, although some researchers have carried out the climate simulation with the regional climate model and implemented sensitivity tests of some external forcing factors, they have not accurately parameterized and analyzed the conditions of the underlying surface [14-16]. Among the various influencing factors of drought, the LUCC has great influence on the frequency of drought, and a lot of research papers have suggested that the LUCC can alter the properties of the underlying surface and consequently lead to the regional climate change [17]. In comparison to other influencing factors of drought, the reasonable arrangement of land use is an effective approach to alleviate the influence of extreme climatic events $[18,19]$. So, it is of great guiding significance to alleviate the influence of extreme climatic events to study the influence of the LUCC on the drought. Besides, the rapid urbanization and ecological construction have caused the conversion of a lot of fertile croplands, which led to the rapid decrease of cropland area and aggravated the landscape fragmentation [19]. Although the subsequent ecological construction has restrained the ecological degradation in the province to some degree, the largescale afforestation projects have further altered the original land cover, and human interference in the land cover influences the spatial pattern of the land surface in a large area [20]. So, what effects will the urbanization and ecological construction have on the climate in Yunnan province?

In this study, the LUCC in Yunnan Province in recent decades was first quantitatively analyzed. Since the severe drought in Southwest China is mainly due to much-less-thannormal precipitation and much-warmer-than-normal surface temperature [3], the Weather Research and Forecasting (WRF) model has been used to simulate and analyze the effects of LUCC on the temperature and precipitation in the future climate forcing field with the LUCC as the driving factor in this study, and the future scenarios of meteorological drought in Yunnan province were further forecasted and analyzed with the meteorological drought composite index in the expectation of providing some reference and support for reasonably arranging the land use, alleviating the influence of extreme climatic events, and improving the hazard prediction in Southwest China.

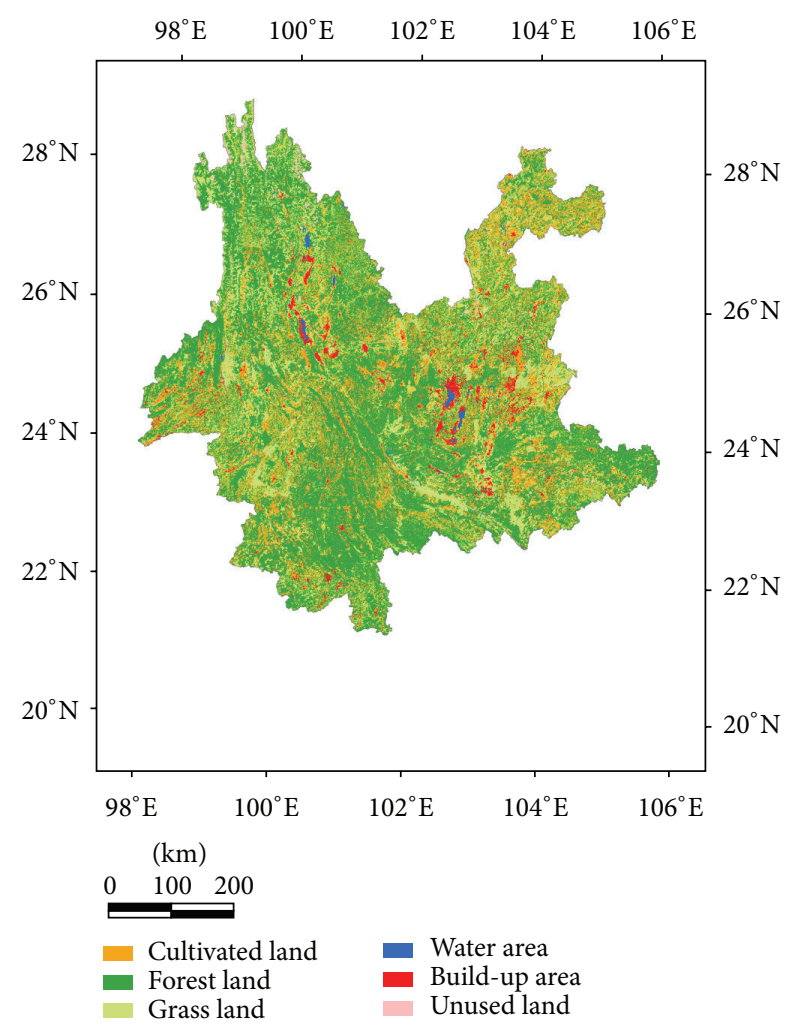

FIGURE 1: Land use pattern of Yunnan province in year 2008.

\section{Characteristics of the LUCC in the Study Area}

In this study, the land use/cover data in years 1985, 1993, 1998, 2003, and 2008 were extracted from the Landsat TM/ETM images in the late 1980s and 1990s by the man-machine interactive visual interpretation, and the main land cover types were summarized and spatially represented as follows. The data suggest that the major land use type in the northwest part is the forest lands, which accounts for more than $58 \%$ of the total land area reaches, while there is a lot of built-up land in the eastern part (Figure 1).

This study implemented spatial statistics and quantitative identification of the change pattern for all the land use types during the study period so as to analyze the major land use/cover change more accurately (Figures 2 and 3 ). The spatial statistics indicates that during 1985-2008, the forest land is the major land use type in Yunnan province and ranks the first in the area increment among all the land use types. The grassland ranks the second in the total area; its increment rate reached 3.09\%, and its total area showed an increasing trend. The cultivated land ranks the third in the total area; although its area increased in some regions, there is a significant decrease of the cultivated land in most regions, and consequently its total area decreased by more than one million ha. Besides, the decrement rate of the cultivated land is the highest among all the land use types, reaching 3.75\%, and the total area decreased by $2 \%$. The very high decrement rate along with the very high increment rate indicated a dramatic 


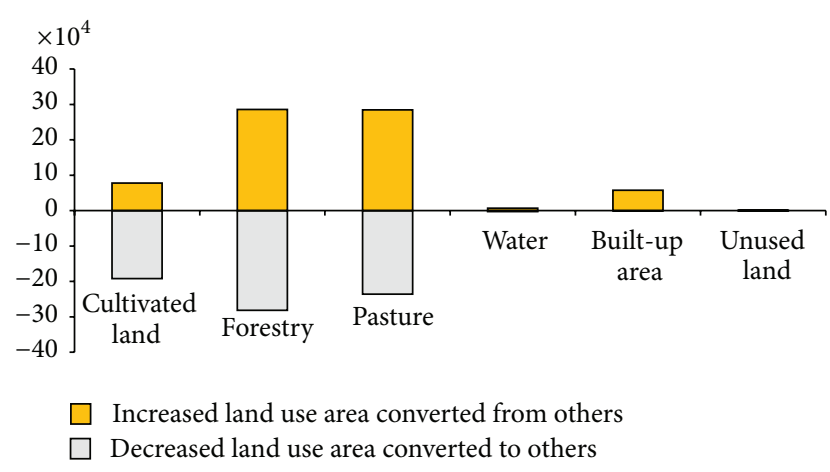

FIGURE 2: Area changes of major land use types in Yunnan province during 1985-2008.

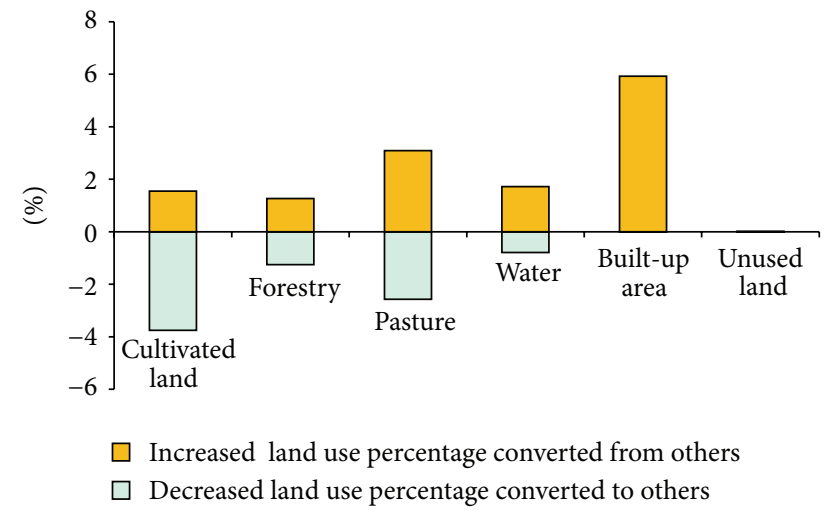

FIGURE 3: Changes of percentage of major land use types in Yunnan province during 1985-2008.

variation in the cultivated land in Yunnan province. The water bodies showed an increasing trend, with an increment rate of approximately $1 \%$. By comparison, the built-up land accounts for the least proportion of the total area, which is less than 3\%, while its area changed most significantly, with an increasing rate of $6 \%$. The analysis of the land transfer with an interval of 5 years further confirmed the significant land cover change in Yunnan province. The transfer among the major land use types also indicates that there is more dramatic variation of the land use behind the overall land use change in Yunnan province.

In summary, the urbanization and ecological construction have led to a significant land use change in Yunnan province. Among all the kinds of land use change, the significant decrease of cultivated land is mainly due to the implementation of the policy of returning farmland to forests or grassland. Besides, in view of the resilience of the forest land and grassland, it is very difficult for them to recover to the original state during short periods if damaged. Although there is great lag in the climatic effects of the land use change, the dramatic land use change still will inevitably have some impacts on the ecological environment, lead to the changes of biophysical properties, and consequently influence the frequency of the regional drought.

\section{Model Design}

3.1. Selection of the Parameterization Scheme of the WRF Model. The WRF model includes the WRF Preprocessing System (WPS), WRF-DA, main program, and postprocessor, among which WPS and the main program have been used in this study. The WPS module is mainly used to preprocess the model, for example, to define model domains and interpolate static geographical data to the grids, interpolate the meteorological fields to the model grids, and prepare the input data to the main program of WRF. While the main program of the WRF model is used to carry out numerical simulation with the data prepared with the WPS module, it includes a very distinctive numerical dynamical framework and many advanced physics parameterization schemes.

This study has mainly focused on the land surface parameterization scheme, since the main research object is to analyze the impacts of the underlying surface on the frequency of the drought disaster. The WRF model mainly includes four land surface parameterization schemes, that is, SLAB scheme, NOAH scheme, RUC scheme, and Pleim-Xiu scheme, all of which calculate the flux of various exchanges between the land surface and the atmosphere, for example, the dynamics, sensible, and latent heat and radiation from the perspective of the water balance and energy balance. The comparison of the test results of these schemes indicates that the Noah scheme proves to be more stable and reasonable than other schemes, although it is also the most complex. Therefore, the Noah scheme was adopted in the analysis of the future climatic effects in this study, and the data of the temperature field and moisture field in the Noah scheme were obtained by interpolation with the large-scale climate data. Besides, the parameterization scheme of the WRF model in this study made reference to the parameterization scheme in the localization test of the mesoscale WRF model, which was carried out by Yunnan Institute of Meteorological Science [21]. The specific conditions of the parameterization scheme are as follows. The land surface process scheme was the Noah land surface model, the cumulus parameterization scheme adopted the GrellDevenyi ensemble scheme [22], the radiation scheme was the CAM3 scheme [23], the cloud microphysics scheme was the Kessler microphysics scheme, and the boundary layer process scheme was the YSU scheme. In addition, a triple nested scheme was designed in this study, with three extents of the simulation region, that is, $d 01, d 02$, and $d 03$, among which $d 01$ covers the whole Yunnan-Guizhou Plateau, and $d 03$ mainly covers Yunnan province. The center point of $d 01$ was located at $101.80^{\circ} \mathrm{E}, 24.85^{\circ} \mathrm{N}$, and the Lambert projection was used. Besides, there were also three spatial resolutions in this study, that is, $9 \mathrm{~km}, 3 \mathrm{~km}$, and $1 \mathrm{~km}$.

3.2. Model Validation. This study first localized the land cover data needed by the WRF model in order to test the ability of the WRF model to simulate the change of main climatic factors in Yunnan province. The $1 \mathrm{~km}$ resolution land use/cover data were reclassified and up-scaled into the $20 \mathrm{~km}$ resolution data. Besides, the land surface parameters in the WRF model, including Albedo and LAI, were adjusted on the basis of the MODIS data covering the study area. The climate forcing 


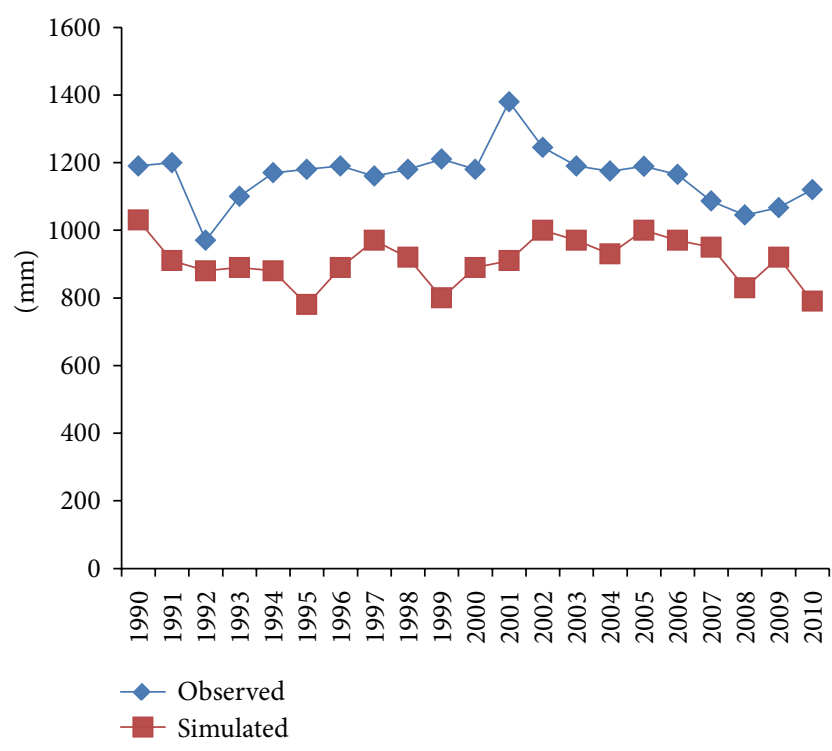

FIGURE 4: Comparison between the observed annual precipitation and simulated annual precipitation with the WRF model in Yunnan province during 1990-2010.

data were run from January 1990 to January 2010, the LUCC data were updated every five years, and finally the simulated data of the precipitation and temperature in Yunnan province during 1990 and 2010 were obtained. In order to verify the accuracy of the simulation, the annual average precipitation of the meteorological stations in Yunnan province has been collected and compared with the simulation results obtained with the standard WRF model (Figure 4). On the whole, the annual precipitation simulated by the model is lower than the data from the meteorological stations, but their overall changing trends are consistent. The correlation coefficient of the simulated and observed annual precipitation during the 20 years is 0.567 and reaches the $95 \%$ level of confidence, indicating that there is a good correlation between them, and the WRF model can simulate the spatiotemporal change of the temperature very well. In summary, there is, high accuracy of the simulation of the temperature and precipitation with the WRF model on the whole.

3.3. Calculation of the Future Meteorological Drought Composite Index. In this study, we referred to GB/T20481-2006 Meteorological Drought Level published by China Meteorological Administration in 2006 and chose the meteorological drought composite index (CI) for analysis [24]. The CI and the values of parameters are based on the standardized precipitation index (SPI) and relative moisture index (MI), which is calculated as follows:

$$
\mathrm{CI}=a Z_{30}+b Z_{90}+c M_{30}
$$

where $Z_{30}$ and $Z_{90}$ refer to the SPI of 30 days and 90 days, respectively, $M_{30}$ refers to the MI of 30 days, $a$ and $b$ are both 0.4 in this study, and $c$ is 0.8 .
The SPI is calculated as follows. Suppose the amount of precipitation during a certain period is $x$, which follows the $\Gamma$ distribution, its probability density function is as follows:

$$
\begin{gathered}
G(x)=\frac{1}{\beta^{\alpha} \Gamma(\alpha)} x^{\alpha-1} e^{-x / \beta} \quad(x \geq 0), \\
\Gamma(\alpha)=\int_{0}^{\infty} x^{\alpha-1} e^{-x} d x,
\end{gathered}
$$

where $\alpha$ is the shape parameter, $\beta$ is the scale parameter, $\Gamma(\alpha)$ is the Gamma function, which is used to calculate the cumulative probability density function $(x)$, and $G(x)$ is further converted as follows:

$$
H(x)=q+(1-q) G(x),
$$

where $q$ is the frequency of 0 in the precipitation array. The SPI is finally obtained by further standardizing $H(x)$ with the Gaussian function. In addition, we referred the Meteorological Drought Level [24] for the estimation of $\alpha, \beta$.

The MI is calculated with the following formula:

$$
\mathrm{MI}=\frac{\sum P}{\sum \mathrm{ET}_{0}},
$$

where $\sum \mathrm{ET}_{0}$ refers to the potential evapotranspiration in the recent 30 days (unit: $\mathrm{mm}$ ) and $\sum P$ is the amount of precipitation in the recent 30 days (unit: $\mathrm{mm}$ ).

The potential evapotranspiration is approximately estimated with the reference method for calculating potential evapotranspiration based on the Penman-Monteith function, which is recommended by the United Nations Food Agriculture Organization (FAO) as follows:

$$
\mathrm{ET}_{0}=\frac{0.408 \Delta\left(R_{s}-G\right)+\gamma(900 /(T+273)) U_{2}\left(\mathrm{VP}_{s}-\mathrm{VP}\right)}{\Delta+\gamma\left(1+0.34 U_{2}\right)},
$$

where $\mathrm{ET}_{0}$ is the reference evapotranspiration $(\mathrm{mm} \cdot \mathrm{d}), R_{s}$ and $G$ refer to the net radiation and soil heat flux, respectively $\left(\mathrm{MJ} \cdot \mathrm{m}^{-2} \cdot \mathrm{d}^{-1}\right), \gamma$ and $\Delta$ refer to the psychomotor constant and the slope of the vapor pressure curve $\left(\mathrm{kPa}^{-1} \mathrm{C}^{-1}\right), U_{2}$ is the wind velocity at $2 \mathrm{~m}$ above the ground $\left(\mathrm{m} \cdot \mathrm{s}^{-1}\right)$, and $\mathrm{VP}_{s}$ and VP represent the saturation vapor pressure and actual vapor pressure $(\mathrm{kPa})$. The parameters used in the calculation process all adopted the standards recommended by FAO.

\section{Analysis of the Risk of Drought in Yunnan Province in the Future}

4.1. Future Spatiotemporal Heterogeneity of the Temperature and Precipitation. After testing the accuracy of the simulation with the WRF model, the simulation test, which used the LUCC data of year 2008 and the climate forcing data during October 2010 and October 2040, was implemented so as to analyze the risk of the meteorological drought. Since the severe drought in the Southwest China is mainly due to much-less-than-normal precipitation and much-warmerthan-normal surface temperature [3], the air temperature at 


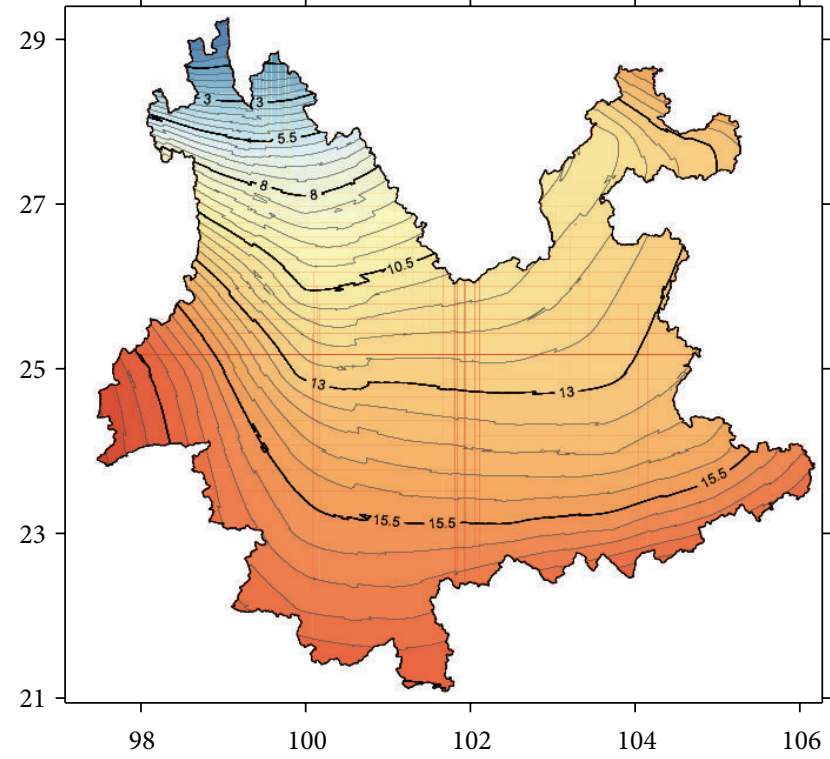

(a)

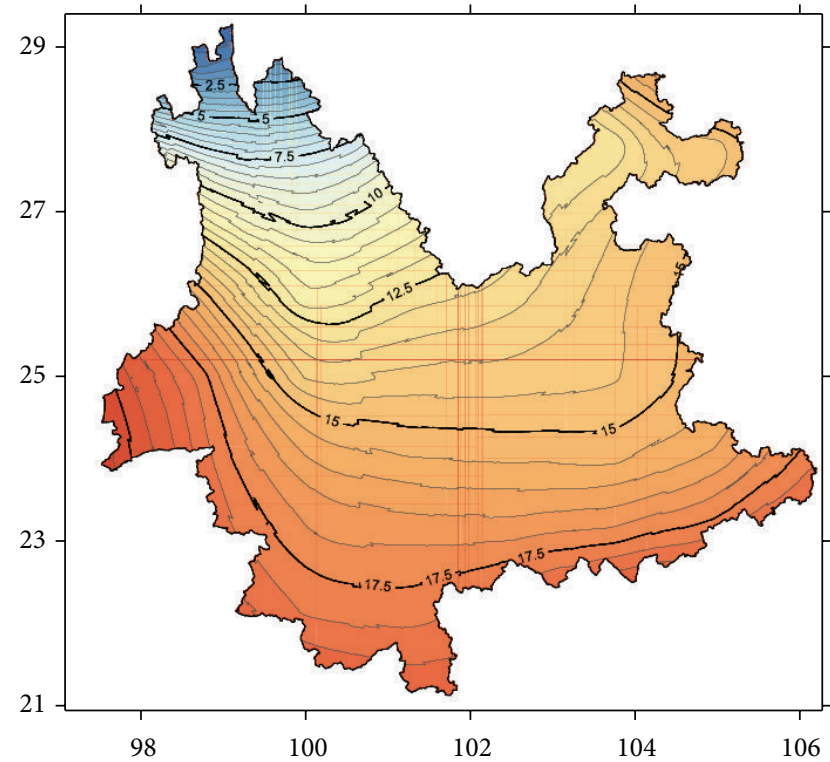

(c)

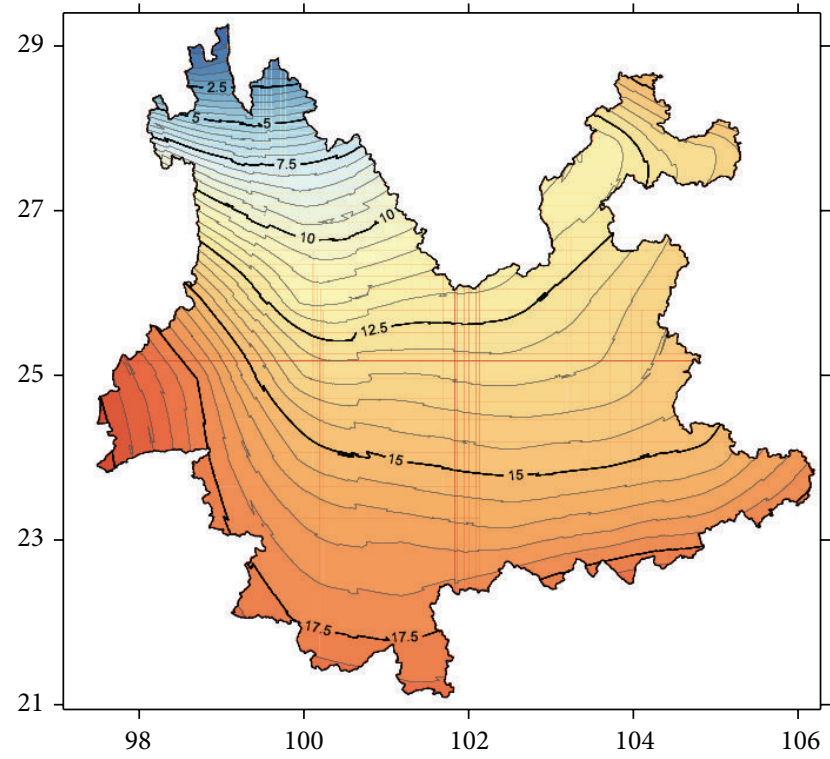

(b)

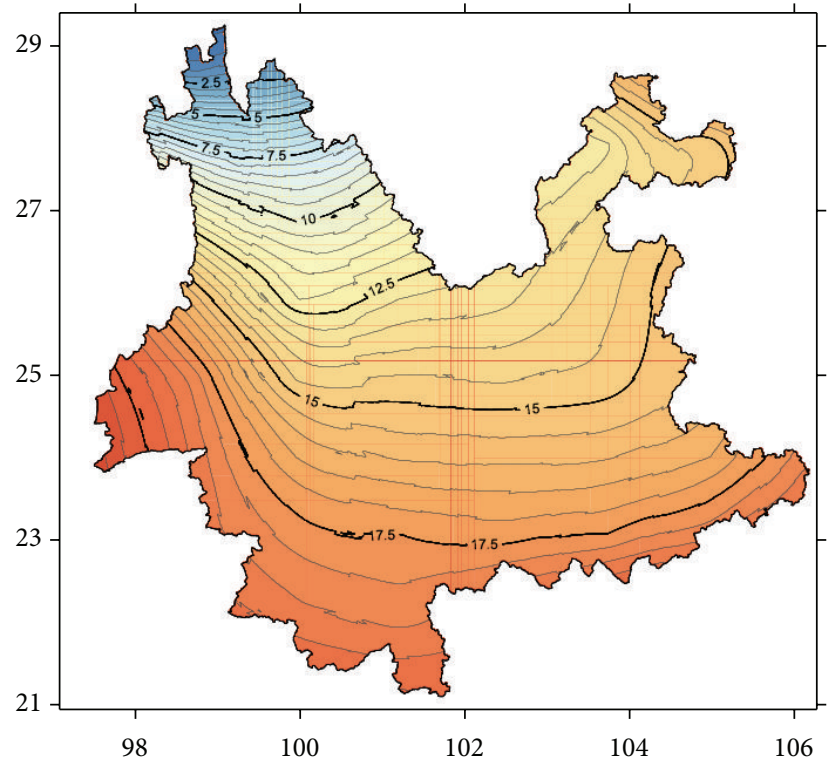

(d)

FIGURE 5: Spatial heterogeneity of the air temperature at $2 \mathrm{~m}$ above the ground in Yunnan province during 2020-2050 (unit: ${ }^{\circ} \mathrm{C}$ ): (a) 2020; (b) 2030; (c) 2040; (d) 2050 .

$2 \mathrm{~m}$ above the ground and the precipitation in the future 40 years were firstly analyzed and represented as follows (Figures 5 and 6 ).

Since the temperature is one of the most important influencing factors of the drought disaster, the time-series data of the spatial heterogeneity of temperature change can reflect the spatial pattern of the risk of drought disaster to some degree. Consistent with the fact that temperature and latitude have a so strong relation, the temperature in Yunnan province increases from the northwest to the southeast on the whole. In addition, the spatial distribution of the temperature in the future 40 years indicates that this spatial pattern of the temperature will not change in the future. If the influence of the underlying surface is not taken into account, the solar radiation angle and the annual sunshine hours will decrease from the south to the north, which is consistent with the decreasing trend from the northwest to the southeast in the future 40 years. Besides, the time-series data suggests that the temperature of the same place will steadily increase by $0.5^{\circ} \mathrm{C} / 10$ years. On the other hand, there is a significant spatial heterogeneity of the regional temperature change, and this heterogeneity cannot be totally explained by latitude and solar radiation angle. The changing trend of every 10 years suggests that the amplitude of variation of the temperature is the least in the northwest part of Yunnan province. The temperature is lower in the northwest part of Yunnan province, 


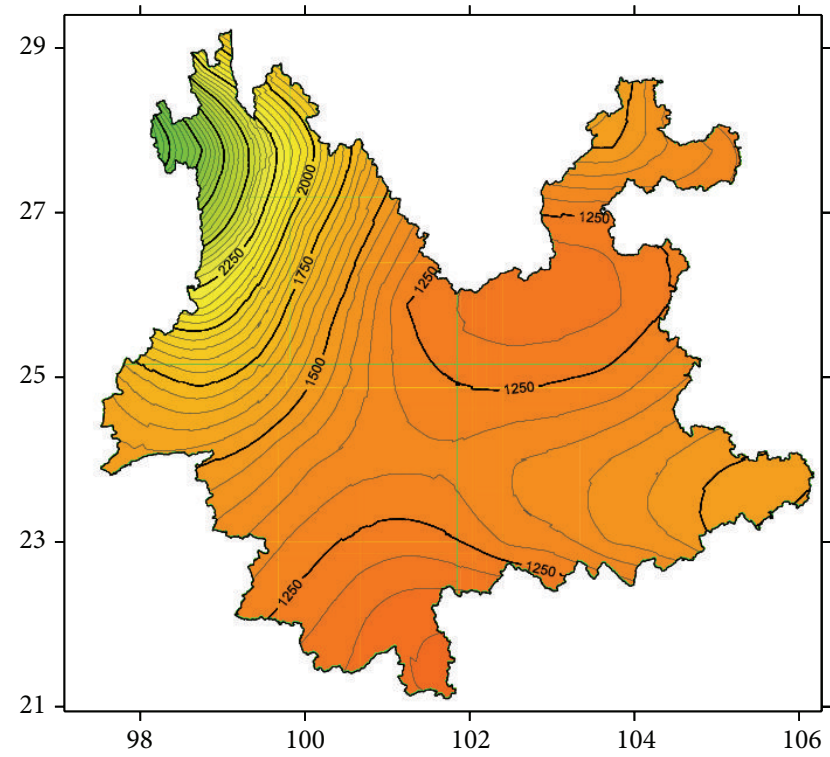

(a)

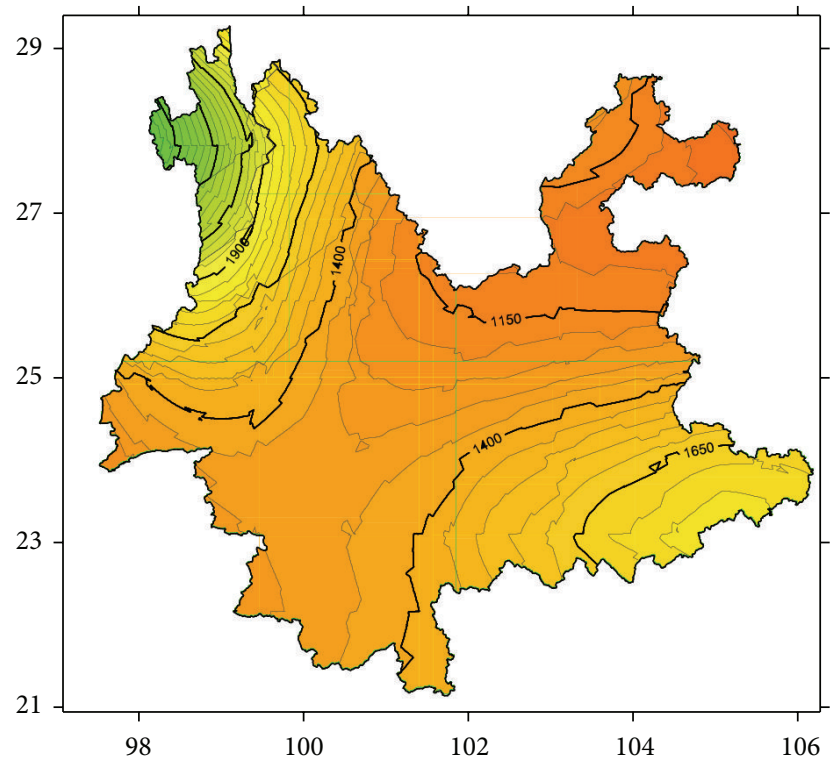

(c)

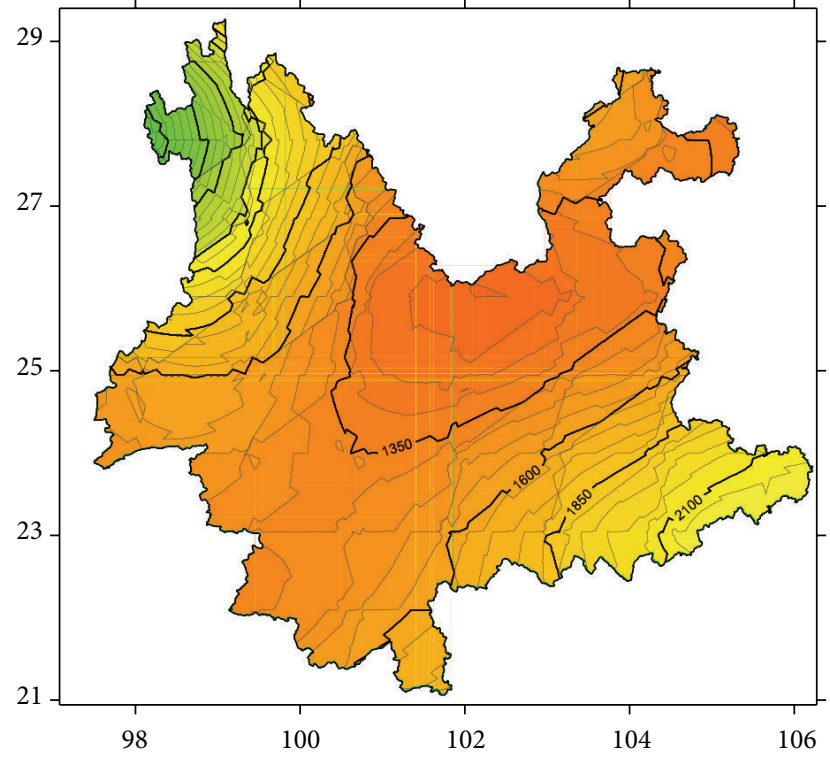

(b)

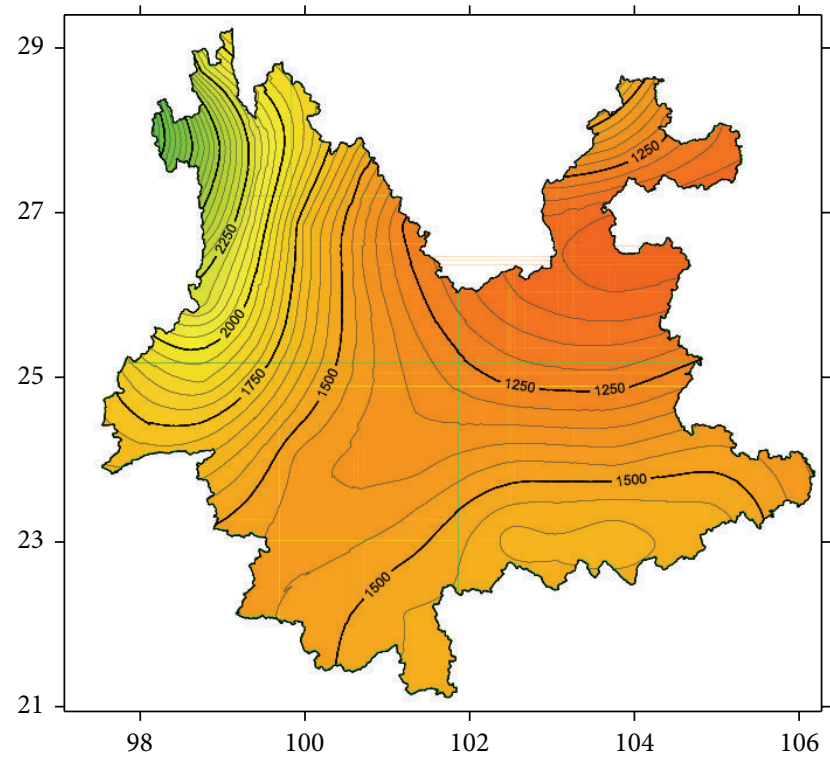

(d)

FIGURE 6: Spatial heterogeneity of precipitation in Yunnan province during 2020-2050 (unit: mm): (a) 2020; (b) 2030; (c) 2040; (d) 2050.

where the amplitude of temperature change is the least. By contrast, there is an obvious temperature rise in the eastern part, and the close to the east it is, the higher the temperature rise is. In addition, the amplitude of temperature rise is relatively large in the regions around Kunming city, and the temperature difference between these regions and other regions will gradually increase, which is mainly due to the significant difference between the land cover in the urban region around Kunming city and other regions.

The precipitation as another important influencing factor of the drought disaster also has a significant influence on the spatiotemporal change of the risk of drought disaster. There is a significant spatial heterogeneity of the precipitation in
Yunnan province during 2020-2050; the precipitation shows vertical differentiation along $23.5^{\circ} \mathrm{N}$ on the whole, and there is the most significant variation of the precipitation in the northwest part, where it will reach $2500 \mathrm{~mm}$ in year 2020 . However, the precipitation in the northwest part will show a first decreasing and then increasing trend, first reaching $2850 \mathrm{~mm}$ in year 2030, then declining to $2650 \mathrm{~mm}$ in year 2040, and finally increasing to $3000 \mathrm{~mm}$ in year 2050. This temporal change of precipitation may be related with the change of the future climate forcing field. The precipitation is generally very low in the southern part (e.g., Simao city, Jinghong city), and there is only slight difference of precipitation in this region. The precipitation in the southern part 
TABLE 1: Classification standard of the meteorological drought composite index (CI).

\begin{tabular}{lcc}
\hline Level & Class & CI \\
\hline 1 & No drought & $-0.6<\mathrm{CI}$ \\
2 & Slight drought & $-1.2<\mathrm{CI} \leq-0.6$ \\
3 & Moderate drought & $-1.8<\mathrm{CI} \leq-1.2$ \\
4 & Heavy drought & $-2.4<\mathrm{CI} \leq-1.8$ \\
5 & Extreme drought & $\mathrm{CI} \leq-2.4$ \\
\hline
\end{tabular}

shows an increasing trend on the whole. The significant change of precipitation mainly concentrates in the southeast part and northeast part.

\subsection{Analysis of the Scenario of Drought in the Future with the} WRF Model. After the analysis of the spatial heterogeneity of precipitation and the air temperature simulated by the WRF model, the meteorological data in the future 40 years were simulated with the WRF model, including the daily precipitation, daily temperature, net radiation, soil heat flux, wind velocity at $2 \mathrm{~m}$ above the ground, saturation vapor pressure, actual vapor pressure, and solar radiation. These data were put into the equations from (2) to (5), and the meteorological drought composite index (CI) was calculated with (1) and then classified according to the classification standard of the CI (Table 1). The classification result was finally spatially represented as follows (Figure 7).

The time-series data of the risk of drought in Yunnan province indicate that the regions of no drought during 20202050 mainly concentrate in the northwest part where the main land cover type is the forest. The forest in Yunnan province plays an important role in decreasing the risk of drought in the future; however, it is notable that the degree of drought in the northwest part is aggravating to some degree, and the area with higher risk of drought is expanding in this region, indicating that the forest in the northwest part has been damaged to some degree and some forests have been converted to other land use types. In addition, the regions with the risk of heavy or extreme drought are generally in the southern part, especially the southwest part, where it is greatly influenced by the subtropical high-pressure belt.

The forest plays an important role in regulating the climate and alleviating the drought since it has greater influence on the important biogeophysical parameters of the land surface, for example, the albedo, evapotranspiration, and roughness of the land surface. For example, the albedo of the forest is generally lower than that of other vegetation types [25], which contributes to the decline of the near-surface temperature. Besides, the land surface roughness can influence the turbulent flow between the land surface and the atmosphere and consequently influences the local diffusion flux. Some sensitivity tests indicate that the change of the land surface roughness can make the global temperature increase by $0.29^{\circ} \mathrm{C}$, and the temperature rise is more obvious in the tropical zone, where there is greater variation of the leaf area index and vegetation height [26]. Since the forest has higher land surface roughness, it can lead to more turbulent flow between the land surface and the atmosphere and higher local diffusion flux and consequently causes the decline of the near-surface temperature [26].

In addition, although the urban area accounts for only $3 \%-4 \%$ of the total land area in Yunnan province, the urban land has significant influence on the local and regional climate. What is more important, according to the urbanization planning, the urban area will expand rapidly and consequently exert more influence on the local and regional climate [27]. The city agglomeration as well as the urban effects are not dominated in this province and only occurred in a limited region. For example, in the regions to the east of Yuanjiang river, especially in the regions around Kunming city, there is remarkable conversion of the other land use types to the urban and built-up land, which makes the northeast part become the area with extreme drought by year 2030, and the expansion of the urban and built-up lands can greatly influence the local climate. In the urban regions, there is generally low vegetation coverage and large area of impermeable land surface, which greatly decrease the evapotranspiration of the land surface and make the potential heat flux much higher than that in the regions with higher vegetation coverage and consequently make the near-surface temperature increase greatly and lead to the urban heat island effect. Besides, the urban heat island effect leads to more turbulent flow in the urban district than in the suburban district, makes the moisture content in the atmosphere lower in the urban district than in the suburban district, and consequently leads to the dry land effect.

\section{Conclusion}

The distinctive geographic position, various terrain, and complex climate conditions all make it very difficult to simulate and forecast the regional climatic effects in Yunnan province. On the basis of the analysis of the land use/cover change in the past decades, this study simulated the change of influencing factors of drought in Yunnan province with the WRF model. This study has mainly focused on the spatiotemporal heterogeneity of the risk of drought and the characteristics of its change under the scenario of accelerated urbanization and the large-area forest since the urbanization and ecological construction have significant influence on the land use/cover change.

In comparison to other vegetation types, the large area of forest in Yunnan province has played a more significant role in decreasing the risk of drought. On the whole, the better the vegetation cover is, the lower the risk of drought is. By contrast, the landscape structure changes due to the urban expansion increase the risk of drought to some degree. The changes of the underlying surface due to the urbanization can influence various physical processes such as the energy balance of the land surface and consequently change the climate in a large area. All these impacts act at a certain temporal and spatial scale, for example, the land use/cover change can influence the albedo of the land surface and consequently influences the regional temperature in the short and medium terms. Besides, the land use/cover change has more effects on the regional scale, but the land-atmosphere feedbacks can 


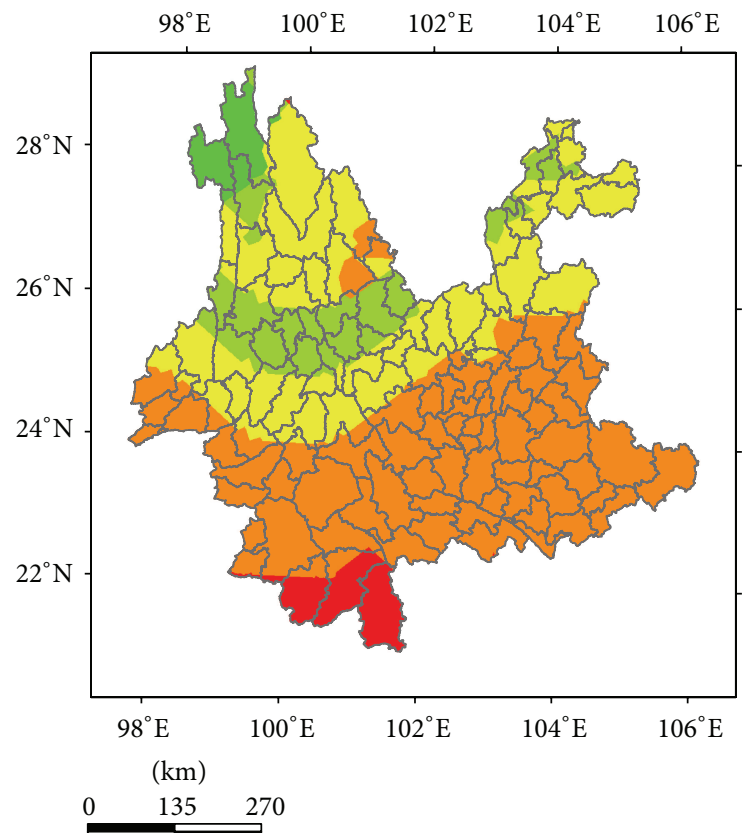

(a)

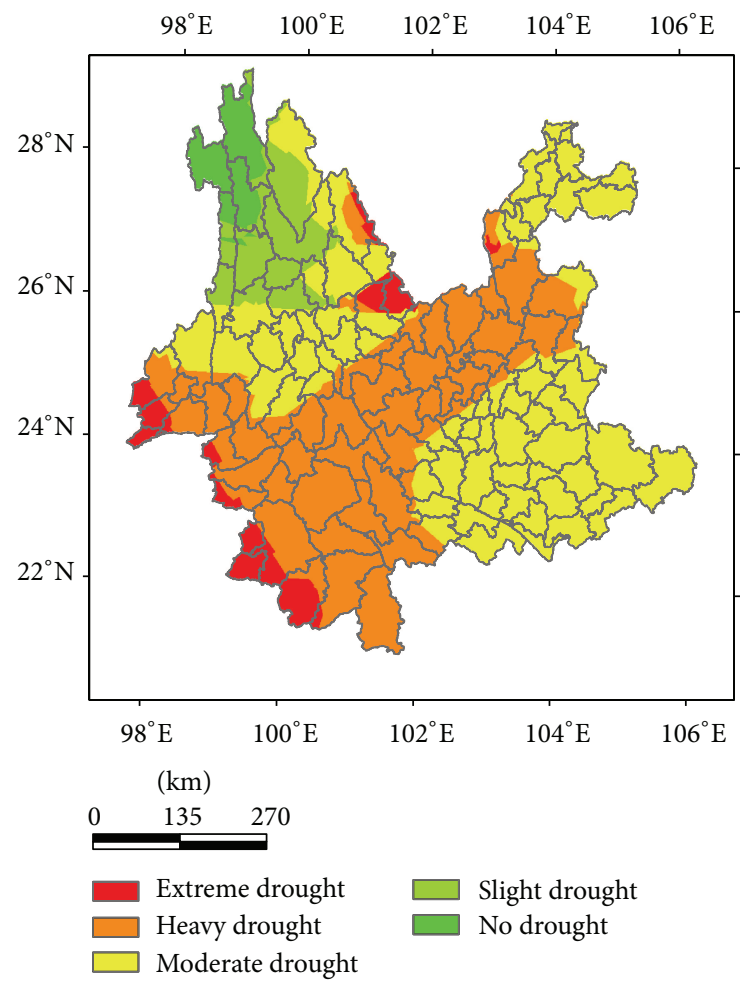

(c)

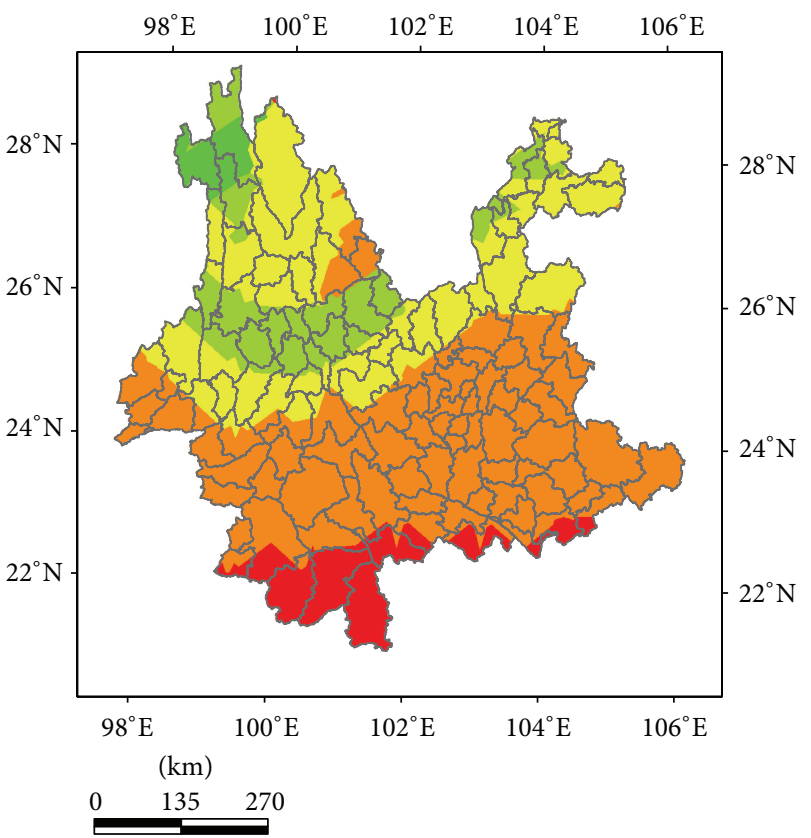

(b)

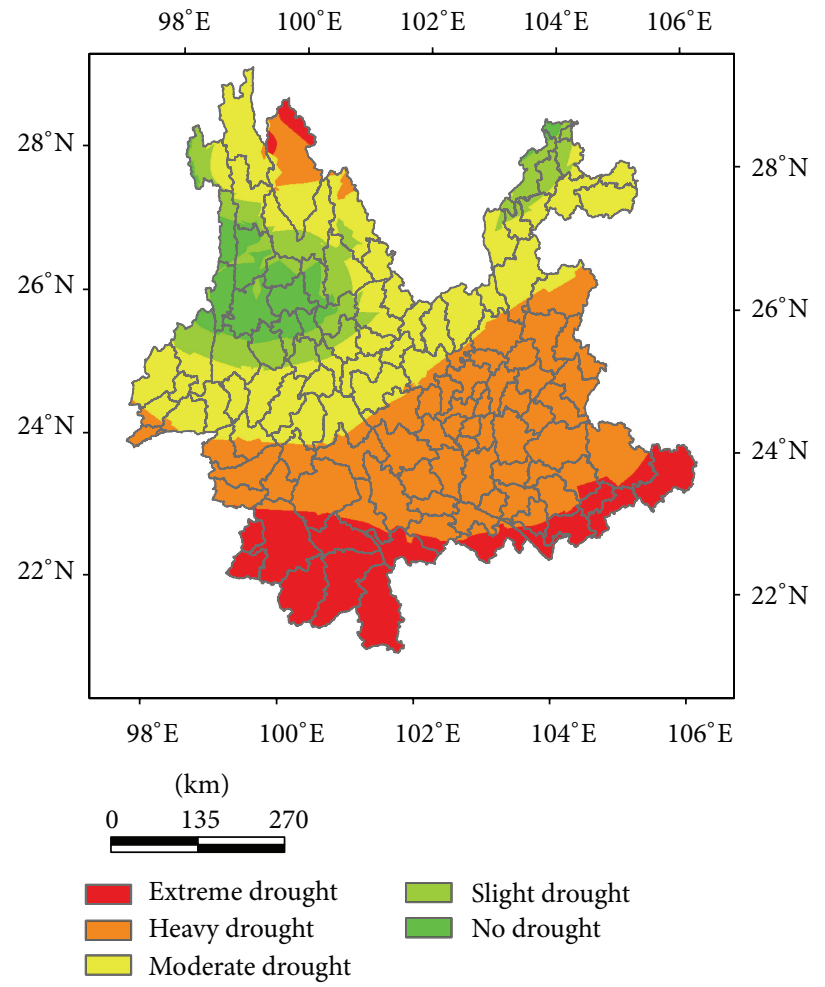

(d)

FIGURE 7: Spatial pattern of the risk of drought in Yunnan province during 2020-2050: (a) 2020; (b) 2030; (c) 2040; (d) 2050.

influence the effects of the global climate change on the regional meteorological drought to the global climate change by altering the albedo of the land surface, soil moisture, and the evaporation process.
The impacts of the land use/cover change in Yunnan province on the regional climate are the combined effects of the biogeophysical processes and biogeochemical processes, but this study has mainly taken into account the influence of 
the biogeophysical factors in the calculation of the meteorological drought composite index. It is still necessary to carry out more indepth research on how to embed the biogeochemical factors into the WRF model and build a more reasonable and reliable meteorological drought index. Besides, there are various climate types in Yunnan province, and there are also various causes of the drought disaster, and this study has mainly focused on the simulation and forecast of the risk of drought due to the LUCC in the future. In order to forecast the degree and frequency of drought more accurately, it is necessary to quantitatively analyze the characteristics and effects of the drought; more meteorological factors should be taken into account in the climate model and numerical analysis, for example, the monsoon wind, atmosphere circulation, and changes in the ocean temperature.

\section{Acknowledgments}

This research was financially supported by the National Department Public Benefit Research Foundation of the Ministry of Land and Resources of China (Grant no. 201311001-5). In addition, the authors appreciate the reviewers and editors for the positive remarks and insightful comments as well as suggestions.

\section{References}

[1] J. Romm, “Desertification: the next dust bowl," Nature, vol. 478, no. 7370 , pp. 450-451, 2011.

[2] D. A. Wilhite, "Drought as a natural hazard: concepts and definitions," Drought: A Global Assessment, vol. 1, pp. 3-18, 2000.

[3] E. Lu, Y. Luo, R. Zhang, Q. Wu, and L. Liu, "Regional atmospheric anomalies responsible for the 2009-2010 severe drought in China," Journal of Geophysical Research D, vol. 116, no. 21, Article ID D21114, 2011.

[4] A. Wang, D. P. Lettenmaier, and J. Sheffield, "Soil moisture drought in China, 1950-2006," Journal of Climate, vol. 24, no. 13, pp. 3257-3271, 2011.

[5] H. Huang, Q. Li, Y. Gao, A. Zhong, H. Chen, and J. Li, "Diagnosis of the severe drought in Autumn/Winter 2009-2010 in Yunnan Province," Tropical Geography, vol. 31, no. 1, pp. 28-33, 2011.

[6] Y. Zhang, R. Yu, J. Li, W. Yuan, and M. Zhang, "Dynamic and thermodynamic relations of distinctive stratus clouds on the lee side of the Tibetan Plateau in the cold season," Journal of Climate, 2013.

[7] J. Cheng and M. Xie, "The analysis of regional climate change features over Yunnan in recent 50 years," Progress in Geography, vol. 27, no. 5, pp. 19-26, 2008.

[8] Z. Chi, Z. Du, Z. Chen et al., "Analyses on meteorological elements and general circulation of drought in Guizhou Province in Autumn-Winter-Spring from 2009 to 2010," Plateau Meteorology, vol. 31, no. 1, pp. 176-184, 2012.

[9] J. Yang, D. Gong, W. Wang, M. Hu, and R. Mao, "Extreme drought event of 2009/2010 over Southwestern China," Meteorology and Atmospheric Physics, vol. 115, no. 3-4, pp. 173-184, 2012.

[10] Q. Ye, M. Wang, and J. Han, "Integrated risk governance in the Yungui Plateau, China: the 2008 ice-snow storm disaster," Journal of Alpine Research. In press.
[11] O. L. Phillips, L. E. Aragão, S. L. Lewis et al., "Drought sensitivity of the Amazon rainforest," Science, vol. 323, no. 5919, pp. 13441347, 2009.

[12] M. Zhang, J. He, B. Wang et al., "Extreme drought changes in Southwest China from 1960 to 2009," Journal of Geographical Sciences, vol. 23, no. 1, pp. 3-16, 2013.

[13] M. Yu, Q. Li, M. J. Hayes, M. D. Svoboda, and R. R. Heim, "Are droughts becoming more frequent or severe in China based on the standardized precipitation evapotranspiration index: 19512010?" International Journal of Climatology, 2013.

[14] L. Zou and T. Zhou, "Near future (2016-40) summer precipitation changes over China as projected by a regional climate model (RCM) under the RCP8. 5 emissions scenario: comparison between RCM downscaling and the driving GCM," Advances in Atmospheric Sciences, vol. 30, no. 3, pp. 806-818, 2013.

[15] X. Gao, Y. Shi, D. Zhang, and F. Giorgi, "Climate change in China in the 21st century as simulated by a high resolution regional climate model," Chinese Science Bulletin, vol. 57, no. 10, pp. 1188-1195, 2012.

[16] Y. Zhang, Y. Xu, W. Dong, L. Cao, and M. Sparrow, "A future climate scenario of regional changes in extreme climate events over China using the PRECIS climate model," Geophysical Research Letters, vol. 33, no. 24, Article ID L24702, 2006.

[17] L. Salvati and S. Bajocco, "Land sensitivity to desertification across Italy: past, present, and future," Applied Geography, vol. 31, no. 1, pp. 223-231, 2011.

[18] F. T. de Vries, M. E. Liiri, L. Bjørnlund et al., "Land use alters the resistance and resilience of soil food webs to drought," Nature Climate Change, vol. 2, no. 4, pp. 276-280, 2012.

[19] C. Cheng, "Land use effects on energy and water balancedeveloping a regional land use adapted drought index," Irrigation and Drainage Systems Engineering, vol. 1, no. 2, p. 105, 2012.

[20] Y. Jiang, Y. Lin, and X. Sun, "Green development and ecological construction," in China Green Development Index Report, Current Chinese Economic Report Series, pp. 237-261, Springer, New York, NY, USA, 2011.

[21] D. Xu, W. Man, C. Xinmei, L. Jianyu, and F. Rui, "Localization of operational experiment on the WRF mesoscale numerical modeling system," Meteorological Monthly, vol. 37, no. 01, pp. 39-47, 2011 (Chinese).

[22] G. A. Grell and D. Dévényi, "A generalized approach to parameterizing convection combining ensemble and data assimilation techniques," Geophysical Research Letters, vol. 29, no. 14, pp. 38.1-38.4, 2002.

[23] W. D. Collins, P. J. Rasch, B. A. Boville et al., "Description of the NCAR community atmosphere model (CAM 3. 0)," NCAR Technical Note NCAR/TN-464+STR, 2004.

[24] Q. Zhang, X. Zou, and F. Xiao, Meteorological Drought Level GB/T20481-2006, Standards Press, Beijing, China, 2006.

[25] P. Alton, "A simple retrieval of ground albedo and vegetation absorptance from MODIS satellite data for parameterisation of global land-surface models," Agricultural and Forest Meteorology, vol. 149, no. 10, pp. 1769-1775, 2009.

[26] S. Bathiany, M. Claussen, V. Brovkin, T. Raddatz, and V. Gayler, "Combined biogeophysical and biogeochemical effects of largescale forest cover changes in the MPI earth system model," Biogeosciences, vol. 7, no. 5, pp. 1383-1399, 2010.

[27] Yunnan Provincial Department of Land and Resources, "The overall planning of land use in Yunnan province (2006-2020)," 2009 (Chinese). 

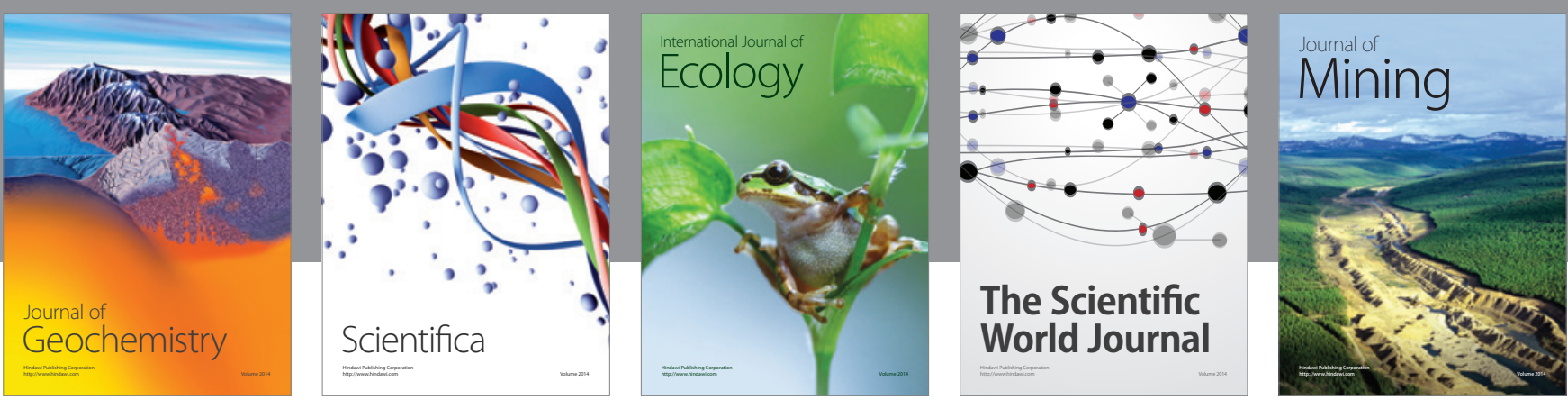

The Scientific World Journal
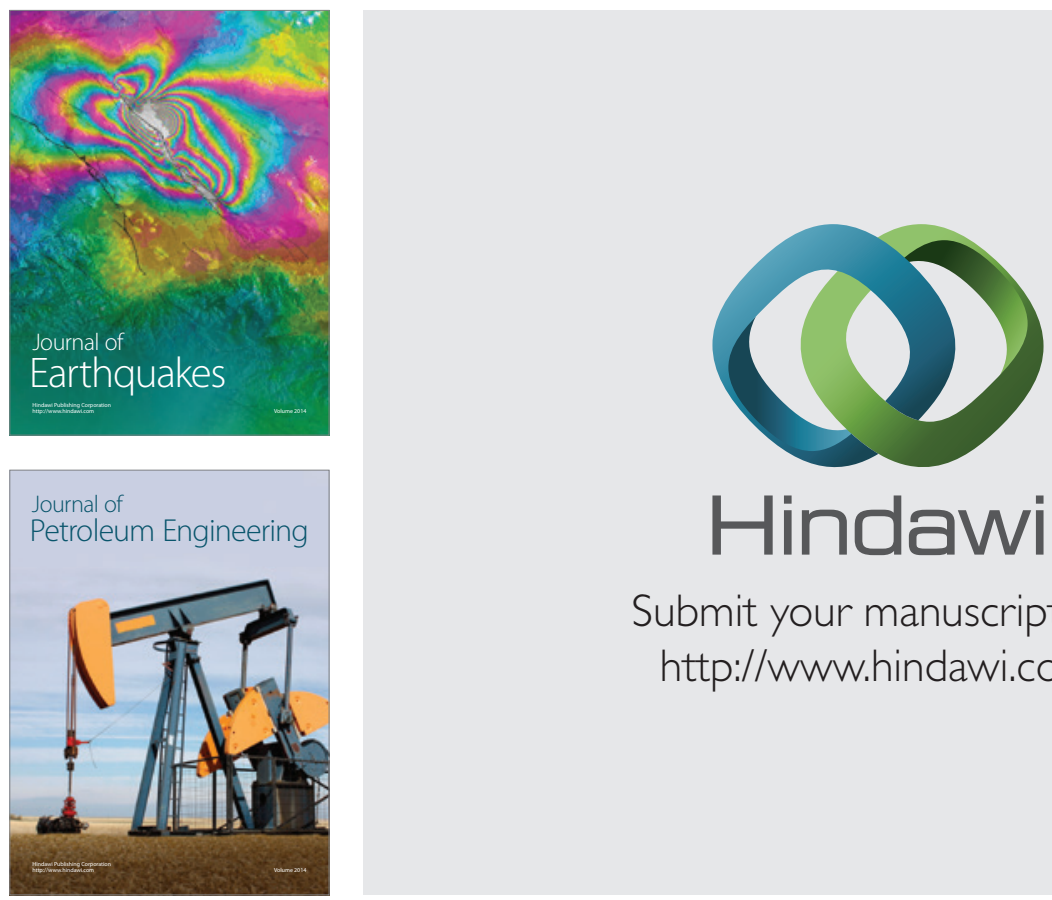

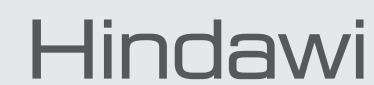

Submit your manuscripts at

http://www.hindawi.com
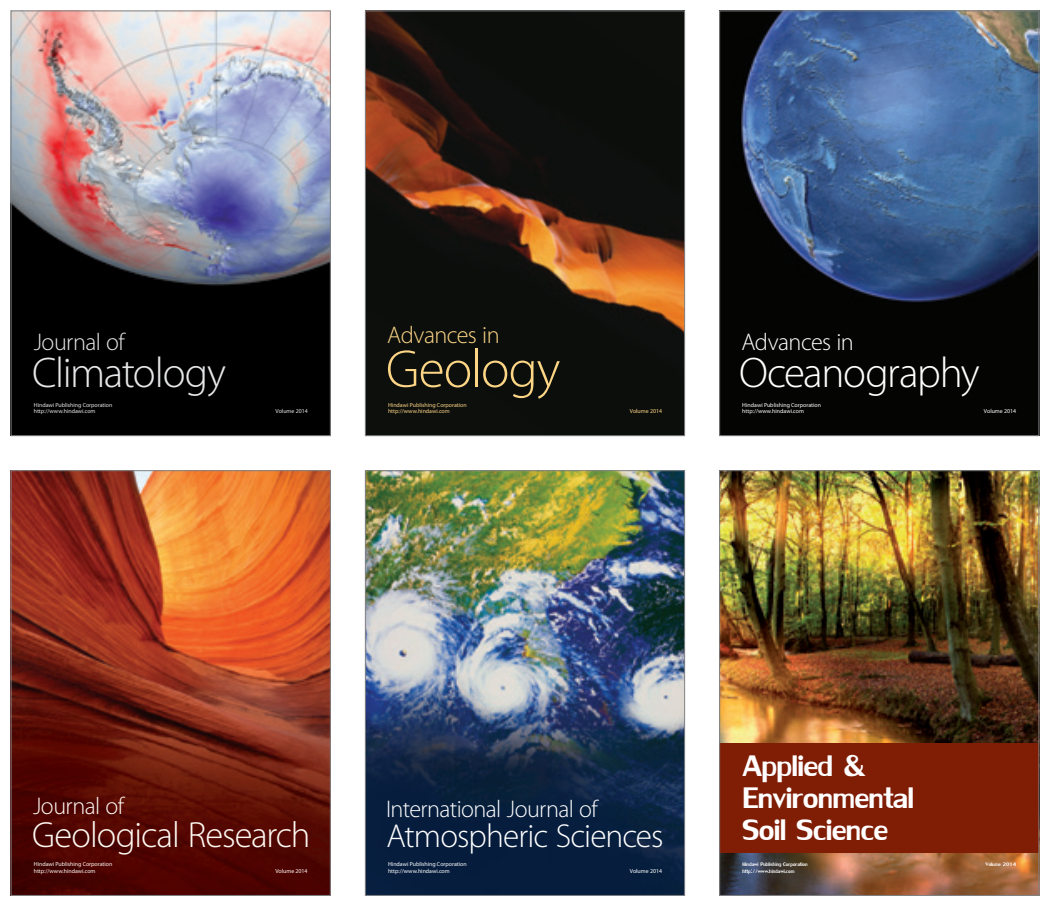
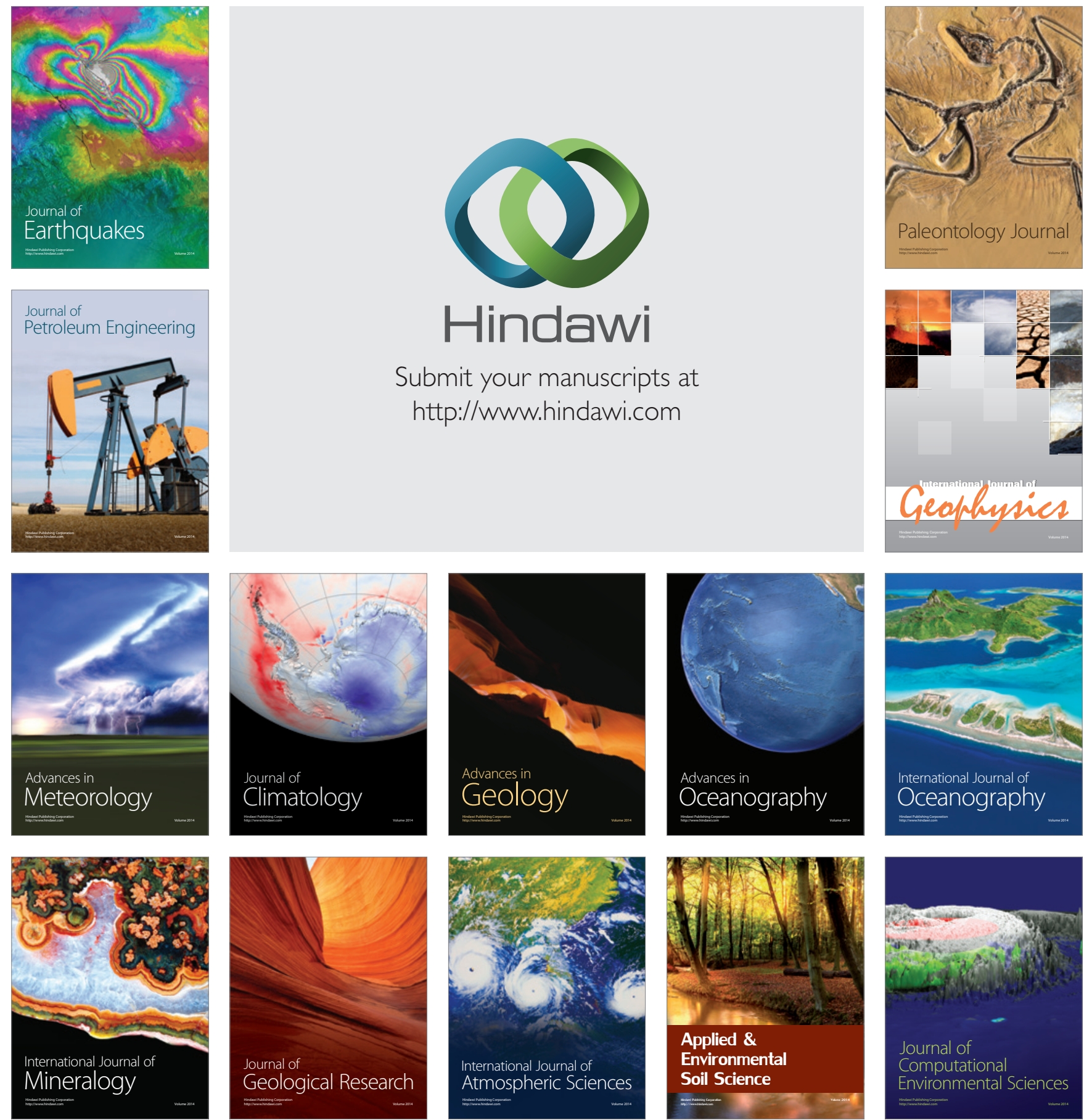